\title{
Fracionamento dos carboidratos pelas equações do Cornell Net Carbohydrate and Protein System de três cultivares de girassol na presença ou não de irrigação ${ }^{1}$
}

\author{
Mário Adriano Ávila Queiroz ${ }^{2}$, Romualdo Shigueo Fukushima ${ }^{3}$, Catarina Abdalla Gomide ${ }^{4}$ \\ 1 Projeto financiado pela Fundação de Amparo à Pesquisa do Estado de São Paulo (FAPESP). \\ 2 Doutorando em Ciência Animal e Pastagem, Escola Superior de Agricultura "Luiz de Queiroz" - USP, Piracicaba, SP. \\ ${ }^{3}$ Faculdade de Medicina Veterinária e Zootecnia - USP, Pirassununga, SP. Bolsista do CNPq. \\ ${ }^{4}$ Faculdade de Zootecnia e Engenharia de Alimentos - USP, Pirassununga, SP.
}

RESUMO - Objetivou-se quantificar as frações de carboidratos pelas equações do Cornell Net Carbohydrate and Protein System (CNCPS) de três cultivares de girassol (Helianthus annuus L.) cultivados na presença ou não de irrigação. A utilização de uma preparação fibrosa, denominada parede celular (PC), nas equações da CNCPS, em substituição à fibra em detergente neutro (FDN) não promoveu diferenças nas frações de carboidratos $B_{1}$ e $C$, mas influenciou as frações $A$ e $B_{2}$. Como os valores da fração $\mathrm{B}_{1}$, obtidos pelo modelo CNCPS foram menores que os teores de amido e pectina determinados em laboratório, supõe-se que a pectina e outros oligossacarídeos da parede celular, solubilizados pela solução de detergente neutro (fibra solúvel), nunca fizeram parte da fração $B_{1}$, e sim da fração $A$. Apesar de os carboidratos da fibra solúvel apresentarem elevadas taxas de degradação, não parece adequada a caracterização da fibra solúvel na fração A. Parece mais adequado que a fibra solúvel (que inclui a pectina) seja alocada a uma fração exclusivamente sua, que pode ser a fração $\mathrm{B}_{2}$, e que seja criada uma nova fração, a $\mathrm{B}_{3}$, para os carboidratos digeríveis da parede celular. Assim, a fração $\mathrm{B}_{1}$ seria composta apenas de amido. A equação da fração $\mathrm{C}$, que estima os carboidratos indigeríveis da parede celular, pode ser simplificada, relacionando a fração indigerível ao teor de lignina na matéria seca, e não à FDN isenta de cinzas e proteína, como atualmente utilizado. Esta proposta tem implicações práticas, uma vez que a fração indigerível da parede celular tem sido expressa em relação à FDN, e não na MS, com base no fato de que os efeitos inibitórios da lignina ocorrem sobre os componentes fibrosos da parede celular vegetal, e não sobre o conteúdo celular.

Palavras-chave: amido, fibra solúvel, lignina, pectina

\section{Carbohydrate fractionation of three sunflower cultivars in the presence or absence of irrigation using the Cornell Net Carbohydrate and Protein System equations}

\footnotetext{
ABSTRACT - This work aimed to estimate the carbohydrate fractions in three sunflower (Helianthus annuus L.) cultivars in the presence or absence of irrigation, using the Cornell Net Carbohydrate and Protein System (CNCPS) equations. The utilization of a fibrous preparation called cell wall (CW) in the CNCPS equations instead of neutral detergent fiber (NDF) showed no differences in the $\mathrm{B}_{1}$ and $\mathrm{C}$ fractions; however, there were differences in the $\mathrm{A}$ and $\mathrm{B}_{2}$ fractions. Because estimates of $\mathrm{B}_{1}$ fraction were lower than wet chemistry determinations of starch and pectin, it was assumed that pectin and other oligosaccharides, that are dissolved by the neutral detergent (soluble fiber), were part of fraction $\mathrm{A}$, but not part of fraction $\mathrm{B}_{1}$. In spite the soluble fiber carbohydrates have high degradation rates, characterization of soluble fiber within fraction A seems inadequate. It seems coherent that soluble fiber (which includes pectin) be allocated exclusively to a fraction which could be fraction $\mathrm{B}_{2}$. In addition, a new fraction $\left(\mathrm{B}_{3}\right)$ should be created for the digestible cell wall carbohydrates. Thus, the fraction $\mathrm{B}_{1}$ would be constituted only by starch. It was verified that the equation for the fraction $\mathrm{C}$, which estimates the indigestible cell wall carbohydrates, could be simplified, expressing lignin on a dry matter basis, instead of ash + protein-free NDF as it is used currently. This finding has a practical implication, because it has been recommended that the indigestible cell wall be related to NDF, and not to DM, on the basis that the inhibitory effects of lignin occur on the plant cell wall fibrous carbohydrates and not on the cell content.
}

Key Words: lignin, pectin, soluble fiber, starch 


\section{Introdução}

Um dos métodos de avaliação do valor nutritivo de forrageiras é o sistema detergente, constituído pela fibra em detergente ácido (FDA) (Van Soest, 1963) e pela fibra em detergente neutro (FDN) (Van Soest, 1967a).

A fibra em detergente neutro é amplamente utilizada pelos nutricionistas de ruminantes para diversas finalidades, incluindo a formulação de rações, as estimativas do conteúdo energético e a predição da ingestão alimentar, entre outras. Entretanto, a fibra em detergente neutro não é parede celular na íntegra, uma vez que a solução de detergente neutro promove a solubilização da pectina e de outros oligossacarídeos, como as $\beta$-glucanas, galactanas e gomas, agrupadas sob a denominação genérica de fibra solúvel em detergente neutro ou polissacarídeos nãoamiláceos e não-componentes da FDN (Hall, 2003). Entretanto, segundo os preconizadores do sistema detergente, a pectina, apesar de estar localizada na parede celular, pode ser incluída na fração que compreende o conteúdo celular, pois preenche os requisitos de polissacarídeo não-amiláceo e é rapidamente digerida no rúmen (Van Soest et al., 1991).

Objetivando aperfeiçoar o sistema detergente para reconhecer as diversas frações de carboidratos e proteínas, com características de solubilidade e degradação distintas, foi proposto o "Cornell Net Carbohydrate and Protein System" (CNCPS) (Fox et al., 1992; Russell et al., 1992; Sniffen et al., 1992). Uma das secções desse sistema avalia as frações protéicas e de carboidratos dos alimentos utilizando equações que estimam a digestão e a passagem dessas frações, considerando a dinâmica da fermentação ruminal (Sniffen et al., 1992). Segundo Nocek \& Russell (1988), a taxa de digestão do alimento no rúmen e particularmente o sincronismo entre a taxa de digestão das proteínas e dos carboidratos pode ter importante efeito sobre os produtos finais da fermentação e sobre a produção animal.

As equações da CNCPS que estimam os carboidratos fibrosos de lenta digestão ( $\left(\right.$ ração $\mathrm{B}_{2}$ ) e a fração indigerível (fração C) incorporam a FDN isenta de cinzas e proteína como um dos seus componentes. Como a FDN não é parede celular na íntegra, pode-se especular que sua substituição por uma preparação que espelhasse com maior fidelidade a parede celular melhoraria as estimativas das frações $B_{2}$ e $C$. Ao contrário da FDN, uma outra preparação fibrosa proposta por Fukushima \& Hatfield (2004), denominada parede celular (PC), mantém a parede celular vegetal praticamente intacta.

O girassol é uma dicotiledônea oleaginosa anual utilizada na alimentação de animais ruminantes, rica em pectina, e que pode ser fornecida tanto na forma de silagem (Tomich et al., 2004) como na forma de forragem verde. Segundo Evangelista \& Lima (2001), o rendimento do girassol por hectare é de 40 a 70 toneladas de matéria verde. Como é resistente à estiagem, pois sua capacidade de extrair água do solo é alta, adotou-se neste estudo uma comparação entre as plantas produzidas nos sistemas convencional (sequeiro) e com irrigação.

Este trabalho foi realizado com os objetivos de estimar pelo modelo CNCPS as frações de carboidratos de três cultivares de girassol, irrigados ou não, e verificar a existência de divergências nos resultados das frações de carboidratos ao empregar a parede celular em substituição à FDN nas equações do sistema Cornell.

\section{Material e Métodos}

Oexperimento foi conduzido na Faculdade de Zootecnia e Engenharia de Alimentos da Universidade de São Paulo em colaboração com a Faculdade de Medicina Veterinária e Zootecnia, da mesma universidade, ambas localizadas no Campus de Pirassununga, São Paulo. Foram registrados diariamente, de janeiro a maio de 2002, os dados meteorológicos de temperatura média, umidade relativa e precipitação pluviométrica, obtidos em estação meteorológica.

Utilizaram-se três cultivares de girassol (híbridos M-734 e M-742 e cultivar IAC-Uruguai), adubados de acordo com o resultado da análise do solo. Uma parcela das plantas foi cultivada em sequeiro e a outra com irrigação por aspersão, com quantidade variável de água conforme o estádio de desenvolvimento da planta. As plantas foram colhidas aos 80 dias após a semeadura, desidratadas a $65^{\circ} \mathrm{C}$ em estufa de ventilação forçada por 72 horas, trituradas em moinho Wiley com peneira de granulometria de $1 \mathrm{~mm}$ e acondicionadas em frascos de vidro para posteriores análises.

Nas análises, foram avaliados os teores de matéria seca (MS), matéria mineral (MM), proteína bruta (PB), extrato etéreo (EE), conforme métodos descritos por Silva \& Queiroz (2002); fibra em detergente neutro (FDN), FDN livre de cinzas e proteínas (FDNcp), segundo Van Soest et al. (1991); lignina em detergente ácido (LDA), seguindo protocolo experimental descrito por Goering \& Van Soest (1970); amido, pelo procedimento descrito por Pereira \& Rossi Júnior (1994), com prévia extração dos carboidratos solúveis (Hendrix, 1993); açúcares neutros e pectina, segundo as técnicas propostas por Gorshkova et al. (1996).

A preparação fibrosa da parede celular (PC) e a PC livre de cinzas e proteína (PCcp) foi obtida de acordo com protocolo descrito por Fukushima \& Hatfield (2004) e 
consiste no tratamento seqüencial da amostra com água, etanol, clorofórmio e acetona em aparelho de Soxhlet, um solvente por vez. A troca de solvente era realizada quando nenhuma coloração no solvente fosse perceptível.

O conteúdo de carboidratos totais (CT) foi estimado pela diferença: $\mathrm{CT}=100-(\mathrm{PB}+\mathrm{EE}+\mathrm{MM})$.

Sniffen et al. (1992) propuseram o fracionamento dos carboidratos em quatro frações $\left(\mathrm{A}, \mathrm{B}_{1}, \mathrm{~B}_{2} \mathrm{e} \mathrm{C}\right)$, considerando a disponibilidade nutricional e a taxa de degradação ruminal. A fração A, rapidamente degradável no rúmen, é composta principalmente pelos carboidratos solúveis; a fração $\mathrm{B}_{1}$, composta de amido e pectina, possui taxa de degradação superior à taxa de passagem; a fração $\mathrm{B}_{2}$, composta pelos carboidratos fibrosos da parede celular, é de disponibilidade ruminal lenta, portanto susceptível aos efeitos da taxa de passagem; e a fração $C$ representa a parede celular indisponível, incluindo a lignina.

As equações para estas frações são:

2. $\mathrm{A}(\% \mathrm{CT})=[100-\operatorname{amido}(\% \mathrm{CNF})] \times\left[100-\mathrm{B}_{2}-\mathrm{C}\right] / 100$

3. $\mathrm{B}_{1}(\% \mathrm{CT})=\operatorname{amido}(\% \mathrm{CNF}) \times\left[100-\mathrm{B}_{2}-\mathrm{C}\right] / 100$

$B_{2}(\% C T)=100 \times[F D N c p(\% M S)-P I D N(\% P B)$

4. $\times 0,01 \times P B(\% M S)-F D N c p(\% M S) \times 0,01$

$\times \operatorname{Lig}(F D N c p) \times 2,4] / C T(\% M S)$

$C(\% C T)=100 \times[F D N c p(\% M S) \times 0,01$

5. $\times \operatorname{Lig}(\% F D N c p) \times 2,4] / C T(\% M S)$

$\mathrm{Na}$ equação 2, que estima os carboidratos solúveis, o amido é calculado em relação aos carboidratos nãofibrosos. Os carboidratos não-fibrosos (CNF) são constituídos pelo somatório das frações $\mathrm{A}_{\text {e }} \mathrm{B}_{1}$ (carboidratos solúveis, amido e pectina), que, por sua vez, são solúveis na solução de detergente neutro e podem ser expressos pela diferença:

\section{6. $\mathrm{CNF}(\% \mathrm{MS})=100-(\mathrm{PB}+\mathrm{FDNcp}+\mathrm{EE}+\mathrm{MM})$}

As frações $B_{2}$ e $C$ apresentam a lignina expressa na FDN isenta de cinzas e proteína multiplicada por um fator de correção igual a 2,4, descrito por Chandler et al. (1980). Para fins de comparação, todas as quatro frações foram também calculadas com base na parede celular, em vez da FDN. As equações das frações $\mathrm{A}_{\text {e }} \mathrm{B}_{1}$ não empregam o termo FDN diretamente, mas dependem de outras frações que incluem a FDN.

Adotou-se o delineamento inteiramente casualizado com seis tratamentos, em um fatorial $3 \times 2$ (três cultivares e duas irrigações) com seis repetições, totalizando 36 unidades experimentais. Em todas as análises estatísticas, utilizou-se o PROC MIXED do SAS (SAS, 1998). As diferenças entre as médias dos cultivares foram comparadas pelo teste de Tukey a 5\% de significância.

\section{Resultados e Discussão}

A irrigação, nos três cultivares de girassol, aumentou a composição de todos os nutrientes $(\mathrm{P}<0,05)$, exceto extrato etéreo, lignina em detergente ácido e carboidratos totais (Tabelas 1 e 2). O aumento dos nutrientes resultou em aumento também do teor de matéria seca.

A irrigação favoreceu aumento no teor de matéria mineral, que, juntamente com o aumento do conteúdo de matéria seca e de outros nutrientes, indica maior atividade metabólica do girassol produzido com irrigação, principalmente as variedades M-734 e IAC-Uruguai $(\mathrm{P}<0,05)$ (Tabela 1). Na ausência de irrigação, não houve diferenças para essas características entre as variedades $(\mathrm{P}>0,05)$ de girassol.

O conteúdo de proteína bruta também foi maior no girassol cultivado com irrigação $(\mathrm{P}<0,05)$, mais acentuadamente no cultivar IAC-Uruguai (Tabela 1), mas não diferiu entre as variedades $(\mathrm{P}>0,05)$ cultivadas sem irrigação. Quando a planta forrageira apresenta maior disponibilidade protéica e a proteína é de rápida degradação, para que a síntese microbiana no rúmen seja eficiente, é necessário fornecer ao animal fontes de carboidratos de rápida degradação ruminal (Nocek \& Russell, 1988). A irrigação também favoreceu o aumento $(\mathrm{P}<0,05)$ no teor de proteína ligado à porção fibrosa, tanto na FDN (PIDN) como na parede celular (PPC) (Tabela 2). Aparentemente este aumento da proteína na matriz da parede celular acompanhou o da proteína na planta, entretanto, a proteína ligada à parede celular é de baixa disponibilidade nutricional (Van Soest, 1994). O teor de PIDN foi menor que o da proteína embebida na parede celular. A solução de detergente neutro dissolve mais proteína que a de água quente + solventes orgânicos usada na obtenção da preparação parede celular, uma vez que o procedimento FDN emprega sulfito de sódio. Esse reagente foi introduzido no método original objetivando reduzir a contaminação protéica da fibra (Hintz et al., 1996), pois, de acordo com Mertens (2002), o procedimento FDN deveria incorporar, além de uma $\alpha$-amilase, também o sulfito de sódio para remover a proteína da fibra. Neste trabalho a remoção de proteína na FDN com sulfito de sódio não foi completa, igualmente ao observado por Ferreira \& Mertens (2007).

A matriz da parede celular contém proteína, provavelmente com função estrutural, e tem sido sugerida a existência de ligação covalente com a lignina (Whitmore, 1982). A proteína foi excluída da preparação fibrosa por interferir na quantificação da lignina pelo método do ácido sulfúrico, 
Tabela 1 - Composição química (\%MS) do girassol cultivado com ou sem irrigação

\begin{tabular}{|c|c|c|c|c|c|c|}
\hline Irrigação & Cultivar & $\mathrm{MS}^{1}$ & MM & $\mathrm{PB}$ & EE & FDN \\
\hline \multirow[t]{4}{*}{ Não-irrigado } & M-734 & $20,15 b^{\dagger}$ & $8,71 \mathrm{a}$ & $10,39 a$ & $6,07 \mathrm{~b}$ & $34,88 \mathrm{a}$ \\
\hline & M-742 & $19,75 b$ & $8,04 a$ & $10,89 \mathrm{a}$ & $9,15 \mathrm{a}$ & $34,86 \mathrm{a}$ \\
\hline & IAC-Uruguai & $20,83 \mathrm{a}$ & $8,83 \mathrm{a}$ & $10,38 \mathrm{a}$ & $2,23 \mathrm{c}$ & $34,92 \mathrm{a}$ \\
\hline & Média & $20,24 \mathrm{~B}^{\ddagger}$ & $8,52 \mathrm{~B}$ & $10,55 \mathrm{~B}$ & $5,82 \mathrm{~A}$ & $34,89 \mathrm{~B}$ \\
\hline \multirow[t]{4}{*}{ Irrigado } & M-734 & $21,60 \mathrm{a}$ & $9,86 \mathrm{a}$ & $12,09 \mathrm{~b}$ & $4,29 b$ & $36,36 \mathrm{~b}$ \\
\hline & M-742 & $21,75 \mathrm{a}$ & $8,01 \mathrm{~b}$ & $11,97 \mathrm{~b}$ & $7,37 \mathrm{a}$ & $37,01 \mathrm{~b}$ \\
\hline & IAC-Uruguai & $20,32 b$ & $9,74 \mathrm{a}$ & $13,59 \mathrm{a}$ & $1,78 \mathrm{c}$ & $38,93 \mathrm{a}$ \\
\hline & Média & $21,22 \mathrm{~A}$ & $9,20 \mathrm{~A}$ & $12,55 \mathrm{~A}$ & $4,48 \mathrm{~B}$ & $37,43 \mathrm{~A}$ \\
\hline Irrigação & Cultivar & FDNcp & $\mathrm{PC}$ & PCcp & LDA & LDA* \\
\hline \multirow[t]{4}{*}{ Não-irrigado } & M-734 & $34,32 \mathrm{a}$ & $54,35 \mathrm{c}$ & $50,06 \mathrm{~b}$ & $4,69 a$ & $13,66 \mathrm{a}$ \\
\hline & M-742 & $34,03 \mathrm{a}$ & $56,73 \mathrm{a}$ & $51,17 \mathrm{a}$ & $4,64 \mathrm{a}$ & $13,63 \mathrm{a}$ \\
\hline & IAC-Uruguai & $34,20 \mathrm{a}$ & $55,31 \mathrm{~b}$ & $50,37 \mathrm{~b}$ & $4,74 \mathrm{a}$ & $13,86 \mathrm{a}$ \\
\hline & Média & $34,18 \mathrm{~B}$ & $55,46 \mathrm{~B}$ & $50,53 \mathrm{~B}$ & $4,69 \mathrm{~A}$ & $13,72 \mathrm{~A}$ \\
\hline \multirow[t]{4}{*}{ Irrigado } & M-734 & $33,34 \mathrm{c}$ & $57,77 \mathrm{~b}$ & $52,87 \mathrm{c}$ & $4,32 \mathrm{a}$ & $12,96 \mathrm{a}$ \\
\hline & M-742 & $35,90 \mathrm{~b}$ & $57,96 \mathrm{~b}$ & $53,97 \mathrm{~b}$ & $4,29 \mathrm{a}$ & $11,95 \mathrm{~b}$ \\
\hline & IAC-Uruguai & $37,74 \mathrm{a}$ & $61,90 \mathrm{a}$ & $55,93 \mathrm{a}$ & $4,63 \mathrm{a}$ & $12,27 \mathrm{a}$ \\
\hline & Média & $35,66 \mathrm{~A}$ & $59,21 \mathrm{~A}$ & $54,26 \mathrm{~A}$ & $4,41 \mathrm{~A}$ & $12,37 \mathrm{~B}$ \\
\hline
\end{tabular}

${ }^{1}$ MS - matéria seca, PB - proteína bruta, EE - extrato etéreo, FDN - fibra em detergente neutro, FDNcp - FDN corrigida para cinzas e proteína, PC - parede celular, PCcp - PC corrigida para cinzas e proteína, LDA - lignina detergente ácido, LDA* - lignina detergente ácido (na base da FDNcp).

† Médias seguidas de letras minúsculas diferentes, na mesma coluna e com mesma condição de irrigação, diferem entre si $(P<0,05)$.

‡ Médias seguidas de letras maiúsculas diferentes, na mesma coluna e entre as duas condições de irrigação, diferem entre si $(P<0,05)$.

uma das razões para o surgimento da fibra em detergente ácido de Van Soest (1963), que remove a proteína da fibra.

$\mathrm{O}$ teor de extrato etéreo do girassol não irrigado foi superior ao do girassol irrigado $(\mathrm{P}<0,05)$, sobretudo nos híbridos M-734 e M-742 (Tabela 1). O cultivar IAC-Uruguai, tanto com irrigação como sem irrigação, foi o que apresentou a menor concentração de extrato etéreo, resultado que merece mais estudos, de interesse da indústria de óleos vegetais e afins, pois pode estar relacionado à menor concentração de óleo na semente e/ou ao menor número de sementes na inflorescência. Vacas com altas produções de leite necessitam de fontes energéticas concentradas e, nestes casos, o extrato etéreo pode ser fornecido na forma de óleo ou gordura, isoladamente ou complexado com sais de cálcio (Giesy et al., 2002). Desse modo, o girassol pode fazer parte do alimento volumoso, desde que considerados os limites de extrato etéreo na dieta de ruminantes.

Aparentemente, a irrigação aumentou $(\mathrm{P}<0,05)$ a parte fibrosa da planta, ou seja, FDN e parede celular (Tabela 1). Esse aumento foi maior no cultivar IAC-Uruguai. O aumento nos carboidratos da parede celular, na condição irrigada, refletiu na fração $\mathrm{B}_{2}(\mathrm{P}<0,05)$ (Tabela 3$)$, o que era esperado, uma vez que essa fração é constituída dos carboidratos fibrosos da parede celular lentamente digeríveis. Essa observação foi mais evidente nas variedades M-742 e IACUruguai. A importância da correta avaliação da fração $\mathrm{B}_{2}$ dos carboidratos está relacionada ao teor de fibra. Alimentos volumosos com altos teores de FDN possuem maior proporção de fração $B_{2}$, que, por fornecer energia mais lentamente no rúmen, podem afetar a eficiência da síntese microbiana e o desempenho animal (Ribeiro et al., 2001).

Esperava-se que a concentração de lignina em detergente ácido, também componente fibroso da parede celular, seguisse a mesma tendência, entretanto, as concentração desse componente não diferiu $(\mathrm{P}>0,05)$ com a irrigação (Tabela 1), o que indica que a síntese da molécula de lignina pode ser um evento totalmente independente da deposição dos carboidratos fibrosos da parede celular e da irrigação. Balsalobre et al. (2003) também verificaram que a concentração de lignina teve comportamento diferente do observado para os demais componentes da parede celular, pois plantas com menores teores de FDN apresentam maiores teores de lignina. A fração $\mathrm{C}$, composta dos constituintes indigeríveis da parede celular, também não foi influenciada pela irrigação (P>0,05) (Tabela 3). Quando calculados em relação à FDN isenta de cinzas e proteína, os teores de lignina em detergente ácido foram menores $(\mathrm{P}<0,05)$ no girassol cultivado com irrigação, resultado coerente com as maiores concentrações de FDN observadas nas plantas cultivadas com irrigação.

Apesar de a irrigação ter favorecido a deposição dos carboidratos fibrosos, a composição em carboidratos totais (CT) foi maior na condição não irrigada, sobretudo no IACUruguai $(\mathrm{P}<0,05)$, provavelmente em virtude dos maiores 
teores de carboidratos não-fibrosos (Tabela 2), que incluem os açúcares neutros, a pectina e o amido. A fração A dos carboidratos do CNCPS, que inclui açúcares simples, também seguiu a mesma tendência, ou seja, foi maior $(\mathrm{P}<0,05)$ no girassol produzido sem irrigação, entretanto, a fração $B_{1}$ não apresentou alteração ( $\mathrm{P}>0,05)$ (Tabela 3). No girassol irrigado, a maior concentração da fração A foi observada no híbrido M-734. Quando a disponibilidade dos carboidratos de rápida degradação é elevada, é necessário concomitante e adequado suprimento de proteínas rapidamente degradáveis para o perfeito sincronismo de fermentação de carboidratos e proteínas no rúmen (Nocek \& Russell, 1988). Portanto, aparentemente, a irrigação propiciou aumento dos carboidratos fibrosos, o que ocorreu provavelmente à custa dos carboidratos solúveis. Esta observação pode sinalizar a existência de um mecanismo controlador do crescimento e/ou engrossamento da parede celular com a disponibilidade hídrica.

As concentrações de amido (na MS e no CNF) e pectina no girassol não foram influenciadas pela irrigação $(\mathrm{P}>0,05)$ e a variação entre cultivares foi relativamente pequena (Tabela 2). Resultado semelhante foi observado para a fração $B_{1}$ dos carboidratos (Tabela 3 ), constituída de amido e pectina (Sniffen et al., 1992; Fox et al., 2004). No entanto, os valores encontrados para a fração $\mathrm{B}_{1}(1,09$ a $1,25 \%$ dos carboidratos totais) não foram consistentes com os obtidos em análise laboratorial, pois os teores de amido variaram de 0,85 a $0,91 \%$ da MS (1,13 a $1,25 \%$ dos carboidratos totais) e os de pectina, de 10,21 a 12,71\% da MS (14,20 a 17,23\% dos carboidratos totais), um indicativo de que a equação da fração $B_{1}$ talvez não esteja estimando adequadamente as frações de carboidratos nela contidas, ou que os métodos analíticos para as determinações de pectina e amido não estejam refletindo sua real composição. Malafaia et al. (1998) propuseram o somatório das frações $A+B_{1}$ por considerarem a praticidade do cálculo de rações para ruminantes e o aspecto analítico, uma vez que as metodologias de determinação do amido não resultam em valores verossímeis e não apresentam boa repetibilidade, em virtude da heterogeneidade dos tecidos vegetais. Outros autores também optaram por calcular as frações $\mathrm{A}_{\text {e }} \mathrm{B}_{1}$ conjuntamente, por meio do cálculo dos carboidratos não-fibrosos, que pode ser obtido pela subtração da FDNcp dos carboidratos totais (Cabral et al., 2003; Fernandes et al., 2003; Gonçalves et al., 2003; Pereira et al., 2000).

Embora não tenha sido realizada a comparação estatística, os teores de FDN e FDNcp (Tabela 1) foram menores que as preparações de PC e PCcp, respectivamente. Como mencionado anteriormente, a solução de detergente neutro dissolve a pectina (Van Soest et al., 1991) e outros oigossacarídeos, como as $\beta$-glucanas, galactanas, gomas, etc., agrupadas sob a denominação genérica de fibra

Tabela 2 - Composição de algumas frações (\%MS) do girassol cultivado com ou sem irrigação1

\begin{tabular}{|c|c|c|c|c|c|c|}
\hline & Cultivar & PIDN & PPC & $\mathrm{CT}$ & CNF & Açúcar \\
\hline \multirow[t]{4}{*}{ Não-irrigado } & M-734 & $3,14 b$ & $12,90 \mathrm{a}$ & $74,83 \mathrm{~b}^{\dagger}$ & $40,51 \mathrm{~b}$ & $20,04 \mathrm{a}$ \\
\hline & M-742 & $3,76 \mathrm{a}$ & $11,62 b$ & $71,92 \mathrm{c}$ & $37,89 \mathrm{c}$ & $18,51 b$ \\
\hline & IAC-Uruguai & $4,05 \mathrm{a}$ & $11,88 \mathrm{~b}$ & $78,56 \mathrm{a}$ & $44,36 \mathrm{a}$ & $20,07 \mathrm{a}$ \\
\hline & Média & $3,65 \mathrm{~B}$ & $12,13 \mathrm{~B}$ & $75,10 \mathrm{~A}^{*}$ & $40,92 \mathrm{~A}$ & $19,54 \mathrm{~A}$ \\
\hline \multirow[t]{5}{*}{ Irrigado } & M-734 & $5,11 \mathrm{a}$ & $14,31 \mathrm{a}$ & $73,75 b$ & $40,42 \mathrm{a}$ & $18,72 \mathrm{a}$ \\
\hline & M-742 & $5,18 \mathrm{a}$ & $14,34 \mathrm{a}$ & $72,65 \mathrm{c}$ & $36,75 b$ & $18,39 a$ \\
\hline & IAC-Uruguai & $5,91 \mathrm{a}$ & $12,05 \mathrm{~b}$ & $74,89 \mathrm{a}$ & $37,15 \mathrm{~b}$ & $17,29 a$ \\
\hline & Média & $5,40 \mathrm{~A}$ & $13,57 \mathrm{~A}$ & $73,76 \mathrm{~B}$ & $38,10 \mathrm{~B}$ & $18,13 \mathrm{~B}$ \\
\hline & Cultivar & $\mathrm{Am}$ & $\mathrm{Am}(\mathrm{CNF})$ & $\mathrm{Am}(\mathrm{CT})$ & $\mathrm{Pec}$ & PCcp - FDNcp \\
\hline \multirow[t]{4}{*}{ Não-irrigado } & M-734 & $0,91 \mathrm{a}$ & $2,25 \mathrm{a}$ & $1,22 \mathrm{a}$ & $10,80 \mathrm{~b}$ & 15,74 \\
\hline & M-742 & $0,90 \mathrm{a}$ & $2,37 \mathrm{a}$ & $1,25 \mathrm{a}$ & $10,21 b$ & 17,14 \\
\hline & IAC-Uruguai & $0,89 \mathrm{a}$ & $2,01 \mathrm{a}$ & $1,13 b$ & $12,20 \mathrm{a}$ & 16,17 \\
\hline & Média & $0,90 \mathrm{~A}$ & $2,21 \mathrm{~A}$ & $1,20 \mathrm{~A}$ & $11,07 \mathrm{~A}$ & 16,35 \\
\hline \multirow[t]{4}{*}{ Irrigado } & M-734 & $0,85 \mathrm{a}$ & $2,10 \mathrm{a}$ & $1,15 \mathrm{a}$ & $12,71 \mathrm{a}$ & 19,53 \\
\hline & $\mathrm{M}-742$ & $0,88 \mathrm{a}$ & $2,39 \mathrm{a}$ & $1,21 \mathrm{a}$ & $11,58 \mathrm{~b}$ & 18,07 \\
\hline & IAC-Uruguai & $0,87 \mathrm{a}$ & $2,34 \mathrm{a}$ & $1,16 \mathrm{a}$ & $11,14 b$ & 18,19 \\
\hline & Média & $0,87 \mathrm{~A}$ & $2,28 \mathrm{~A}$ & $1,18 \mathrm{~A}$ & $11,81 \mathrm{~A}$ & 18,60 \\
\hline
\end{tabular}

${ }^{1}$ PIDN - proteína insolúvel no detergente neutro (com base na PB), PPC - proteína da parede celular (com base na PB), CT - carboidratos totais, CNF carboidrato não fibroso, Am - amido, Am (CNF) - amido na base de CNF, Am (CT) - amido na base de CT, Pec - pectina, PCcp - FDNcp - estimativa do teor de fibra solúvel.

† Médias seguidas de letras minúsculas diferentes, na mesma coluna e mesma condição de irrigação, diferem $(P<0,05)$ entre si.

‡ Médias seguidas de letras maiúsculas diferentes, na mesma coluna e entre as duas condições de irrigação, diferem $(P<0,05)$ entre si. 
solúvel em detergente neutro (Hall, 2003). Essa solução possui, entre os reagentes utilizados, um quelante de cálcio, o ácido etilenodiaminotetracético (EDTA), que promove a solubilização da pectina. A preparação de parede celular proposta por Fukushima \& Hatfield (2004) preserva, teoricamente, esses carboidratos da parede celular. Portanto, a diferença algébrica PCcp - FDNcp forneceria uma estimativa do teor de fibra solúvel (FS). Como previsto, esses valores foram maiores que as concentrações de pectina determinadas em laboratório (Tabela 2), uma vez que a fibra solúvel incluiria outros carboidratos além da pectina.

A utilização de parede celular nas equações da CNCPS em substituição à FDN não ocasionou diferenças nos teores de carboidratos das frações $B_{1}$ e $C$, mas influenciou as frações $\mathrm{A}$ e $\mathrm{B}_{2}$ (Tabela 3 ). A equação da fração $\mathrm{A}$ não emprega FDN diretamente, mas depende de outras frações que têm FDN. Como a fração A calculada em relação à FDN foi mais elevada que a obtida usando parede celular (Tabela 3), pressupõe-se que a pectina foi incluída na fração $\mathrm{A}$, e não na $\mathrm{B}_{1}$, mesmo porque os teores de $\mathrm{B}_{1}$ foram muito baixos.

E, se a pectina estiver realmente localizada na fração A, e não mais na $B_{1}$, a equação da fração $B_{1}$ poderá ser simplificada, representando apenas o conteúdo de amido, e ser escrita de outra forma:

7. $\mathrm{B}_{1}(\% \mathrm{CT})=100 \times \operatorname{amido}(\% \mathrm{MS}) / \mathrm{CT}(\% \mathrm{MS})$

De fato, os valores de $\mathrm{B}_{1}$ (Tabela 3 ) calculados dessa maneira foram coerentes com as concentrações de amido determinadas laboratorialmente, convertidas para porcentagem de carboidratos totais (Tabela 2). No entanto, utilizando a parede celular, a pectina (e os demais componentes da fibra solúvel) não estaria incluída na fração A, o que é coerente, pois a fibra solúvel continuaria a fazer parte da matriz da parede celular e, neste caso, deveria integrar a fração $B_{2}$ (dos carboidratos lentamente digeríveis no rúmen). Os valores da fração $B_{2}$ foram mais elevados (Tabela 3 ) quando se utilizou parede celular.

Considerando verdadeira a hipótese de que a fibra solúvel estaria incluída na fração $\mathrm{A}$, pela equação tradicional da CNCPS, e que, quando se substitui a FDN pela parede celular nas equações, a fibra solúvel continuaria na fração $\mathrm{B}_{2}$, então, a subtração $A_{(F D N)}-A_{(P C)}$ deve fornecer uma estimativa do teor de fibra solúvel. Do mesmo modo, a diferença $\mathrm{B}_{2(\mathrm{PC})}-\mathrm{B}_{2(\mathrm{FDN})}$ também deve fornecer esse mesmo valor de fibra solúvel. Os resultados, baseados nos dados médios da fração de carboidratos (Tabela 3), foram:

Tabela 3 - Frações de carboidratos obtidas pelas equações do Cornell Net Carbohydrate and Protein System (\%CT) do girassol cultivado com ou sem irrigação

\begin{tabular}{|c|c|c|c|c|c|}
\hline & \multirow[b]{2}{*}{ Cultivar } & \multicolumn{4}{|c|}{ Fração de carboidratos (FDN) } \\
\hline & & A & $\mathrm{B}_{1}$ & $\mathrm{~B}_{2}$ & $\mathrm{C}$ \\
\hline \multirow[t]{4}{*}{ Não-irrigado } & M-734 & $52,92 \mathrm{~b}^{\dagger}$ & $1,22 \mathrm{a}$ & $30,83 \mathrm{a}$ & $15,04 \mathrm{a}$ \\
\hline & M-742 & $51,43 b$ & $1,25 \mathrm{a}$ & $31,83 \mathrm{a}$ & $15,49 \mathrm{a}$ \\
\hline & IAC-Uruguai & $55,33 \mathrm{a}$ & $1,13 b$ & $29,06 \mathrm{~b}$ & $14,47 b$ \\
\hline & Média & $53,23 A^{\ddagger}$ & $1,20 \mathrm{~A}$ & $30,57 \mathrm{~B}$ & $15,00 \mathrm{~A}$ \\
\hline \multirow[t]{6}{*}{ Irrigado } & M-734 & $53,65 \mathrm{a}$ & $1,15 \mathrm{a}$ & $31,14 \mathrm{~b}$ & $14,07 \mathrm{~b}$ \\
\hline & M-742 & $49,36 b$ & $1,21 \mathrm{a}$ & $35,26 \mathrm{a}$ & $14,17 b$ \\
\hline & IAC-Uruguai & $48,44 b$ & $1,16 \mathrm{a}$ & $35,55 \mathrm{a}$ & $14,85 \mathrm{a}$ \\
\hline & Média & $50,48 \mathrm{~B}$ & $1,17 \mathrm{~A}$ & $33,98 \mathrm{~A}$ & $14,36 \mathrm{~A}$ \\
\hline & & \multicolumn{4}{|c|}{ Fração de carboidratos (PC) } \\
\hline & Cultivar & A & $\mathrm{B}_{1}$ & $\mathrm{~B}_{2}$ & $\mathrm{C}$ \\
\hline \multirow[t]{4}{*}{ Não-irrigado } & M-734 & $31,97 \mathrm{a}$ & $1,22 \mathrm{a}$ & $51,78 \mathrm{~b}$ & $15,03 \mathrm{a}$ \\
\hline & M-742 & $27,08 \mathrm{~b}$ & $1,23 \mathrm{a}$ & $56,20 \mathrm{a}$ & $15,49 \mathrm{a}$ \\
\hline & IAC-Uruguai & $35,11 \mathrm{a}$ & $1,14 \mathrm{~b}$ & $49,28 b$ & $14,47 b$ \\
\hline & Média & $31,39 \mathrm{~A}$ & $1,20 \mathrm{~A}$ & $52,42 \mathrm{~B}$ & $15,00 \mathrm{~A}$ \\
\hline \multirow[t]{4}{*}{ Irrigado } & M-734 & $26,39 a$ & $1,12 \mathrm{a}$ & $58,42 b$ & $14,07 \mathrm{~b}$ \\
\hline & M-742 & $24,71 \mathrm{~b}$ & $1,23 \mathrm{a}$ & $59,89 \mathrm{a}$ & $14,17 \mathrm{~b}$ \\
\hline & IAC-Uruguai & $24,61 b$ & $1,09 \mathrm{a}$ & 59,65 a & $14,65 \mathrm{a}$ \\
\hline & Média & $25,24 \mathrm{~B}$ & $1,15 \mathrm{~A}$ & $59,32 \mathrm{~A}$ & $14,30 \mathrm{~A}$ \\
\hline
\end{tabular}

† Médias seguidas de letras minúsculas diferentes, na mesma coluna, dentro de fração e mesma condição de irrigação, diferem ( $\mathrm{P}<0,05)$ entre si.

₹ Médias seguidas de letras maiúsculas diferentes, na mesma coluna, dentro de fração e entre as duas condições de irrigação, diferem ( $<<0,05)$ entre si. 
$\mathrm{A}_{(\mathrm{FDN})}-\mathrm{A}_{(\mathrm{PC})}=21,84 \%$ (girassol não-irrigado) e 25,24\% (girassol irrigado)

$\mathrm{B}_{2(\mathrm{PC})}-\mathrm{B}_{2(\mathrm{FDN})}=21,85 \%$ (girassol não-irrigado) e $25,34 \%$ (girassol irrigado)

Essa semelhança nos resultados era esperada, pois reflete o valor de fibra solúvel, que teria apenas mudado de fração. A diferença PCcp - FDNcp, uma estimativa do teor de fibra solúvel, confirma essa teoria. Esses valores (os valores de PCcp e FDNcp na Tabela 1 foram expressos na MS), em relação aos carboidratos totais, foram:

PCcp - FDNcp = fibra solúvel em detergente neutro $\mathrm{PCcp}-\mathrm{FDNcp}=67,28-45,51=21,77$ (girassol não-irrigado) PCcp - FDNcp $=73,56-48,34=25,22$ (girassol irrigado)

Esses dados confirmam a hipótese de que a pectina e os demais oligossacarídeos estariam mesmo incluídos na fração $\mathrm{A}$, e não na fração $\mathrm{B}_{1}$, quando utilizadas as equações da CNCPS. Entretanto, caracterizar a fibra solúvel dentro de uma fração de carboidratos rapidamente degradáveis, juntamente com açúcares e ácidos orgânicos (fração A), não parece ser adequado, embora os compostos da fibra solúvel tenham elevadas taxas de degradação. Similarmente, a localização da fibra solúvel na fração $\mathrm{B}_{2}$ (dos carboidratos lentamente digeríveis no rúmen) não tem lógica. Parece que o mais indicado seria a alocação da fibra solúvel, determinada pela diferença PCcp - FDNcp, para uma fração exclusiva para ela, que poderia ser a mesma fração $\mathrm{B}_{2}$. E, para os carboidratos fibrosos digeríveis da parede celular, uma nova fração seria denominada, a fração $B_{3}$. Como a pectina não mais faria parte da fração $B_{1}$, esta seria constituída exclusivamente de amido.

Recentemente, Lanzas et al. (2006) propuseram um esquema expandido das frações de carboidratos que aumenta a fração A e subdivide a fração $B$. Esse novo esquema seria composto pelas seguintes frações: $A_{1}=$ ácidos acético, propiônico e butírico; $\mathrm{A}_{2}=$ ácido láctico; $\mathrm{A}_{3}=$ ácidos orgânicos; $\mathrm{A}_{4}=$ açúcares; $\mathrm{B}_{1}=$ amido; $\mathrm{B}_{2}=$ fibra solúvel; $\mathrm{B}_{3}=\mathrm{FDN}$ disponível e fração $\mathrm{C}=$ FDN não-disponível. Estas frações foram sugeridas com base em dados de acervo obtido com diversos alimentos para gado leiteiro. Nesta pesquisa também houve indicação para a mesma separação das frações B. Entretanto, foram utilizados dados laboratoriais para comparar a substituição da FDN pela parede celular nas equações de carboidratos do CNCPS. Tylutki et al. (2007), ao lançarem a mais recente versão do modelo CNCPS, incorporaram no modelo este esquema de carboidratos expandidos.

A equação da fração C, que representa a parede celular indigerível, em que a lignina é expressa em relação à FDN isenta de cinzas e proteína, foi utilizada ou citada por diversos autores (Traxler et al., 1998; Malafaia et al., 1998; Barcelos et al., 2001; Ribeiro et al., 2001; Balsalobre et al., 2003; Gonçalves et al., 2003) e empregada nas exigências nutricionais do gado de leite (NRC, 2001). Em modelos matemáticos para estimar valores nutricionais e de energia em alimentos, tambémé utilizada a razão entre lignina e FDN, só que elevada ao expoente 0,667 (Conrad et al., 1984; Weiss et al., 1992). Detmann et al. (2004) utilizaram a equação C ou a equação proposta por Conrad et al. (1984) para avaliar a fração indigerível da FDN em gramíneas tropicais.

Um dos seus principais constituintes da fração $\mathrm{C}$ é a FDN e como os valores numéricos da FDN foram completamente diferentes da parede celular (Tabela 1), esperava-se que as estimativas da fração $\mathrm{C}$ fossem também diferentes entre si, o que não ocorreu. Independentemente se foi utilizada FDN ou parede celular na equação, o resultado foi exatamente o mesmo (Tabela 3). Esses termos se cancelavam durante o cálculo da fração $\mathrm{C}$, como algebricamente demonstrado a seguir.

De acordo com Sniffen et al. (1992), a equação para a fração Cé:

$$
\begin{aligned}
& C(\% C T)=100 \times[F D N c p(\% M S) \times 0,01 \\
8 . & \times \operatorname{Lig}(\% F D N c p) \times 2,4] / C T(\% M S)
\end{aligned}
$$

Que pode ser escrita da seguinte forma:

$$
\text { 9. } \mathrm{C}(\% \mathrm{CT})=100 \times \frac{\left.\frac{[\mathrm{FDNcp}(\% \mathrm{MS})}{100} \times \operatorname{Lig}(\% \mathrm{FDNcp}) \times 2,4\right]}{\mathrm{CT}(\% \mathrm{MS})}
$$

ou:

$$
\text { 10. } \mathrm{C}(\% \mathrm{CT})=100 \times \frac{\left[\frac{\mathrm{FDNcp}(\% \mathrm{MS})}{100} \times \frac{\operatorname{Lig}(\% \mathrm{MS}) \times 100}{\mathrm{FDNcp}(\% \mathrm{MS})} \times 2,4\right]}{\mathrm{CT}(\% \mathrm{MS})}
$$

Os termos FDNcp $(\% M S)$ e 100 da equação acima se cancelam uns com os outros, portanto, a equação da fração $C$ pode ser finalmente escrita da seguinte forma:

\section{1. $\mathrm{C}(\% \mathrm{CT})=100 \times[\operatorname{Lig}(\% \mathrm{MS}) \times 2,4] / \mathrm{CT}(\% \mathrm{MS})$}

Essa equação é resultante de uma simplificação algébrica da equação original de Sniffen et al. (1992), mais simples e de uso mais direto, mas diferente pelo simples fato de que, na equação de Sniffen et al. (1992), a fração indigerível da parede celular é expressa em relação ao teor de lignina na FDN livre de cinzas e proteína, enquanto, na equação proposta neste estudo, a fração indigerível é descrita em relação ao teor de lignina na matéria seca. Em outras palavras, a fração indigerível pode ser obtida independentemente da 
FDN e não exige determinação prévia do conteúdo de cinzas e proteína na FDN.

Esta constatação tem algumas implicações. A lignina tem ação deletéria sobre os carboidratos da parede celular, e não sobre o conteúdo celular (Van Soest, 1994). Desse modo, Van Soest (1967b) sugeriu que se deveria evitar relacionar digestibilidade da FDN ao conteúdo de lignina na matéria seca. Traxler et al. (1998), no entanto, observaram que os coeficientes de correlação relacionando indigestibilidade da MS ao conteúdo de lignina na matéria seca foram melhores que quando o conteúdo de lignina foi expresso em relação à FDN. Entretanto, esses autores creditaram esta observação ao efeito da maturidade, uma vez que o teor de FDN aumenta enquanto a concentração de $\mathrm{PB}$ e o conteúdo celular reduzem com o avançar da maturidade.

Também merece mais estudos a técnica analítica de determinação da concentração de lignina. Um método que forneça valores questionáveis de lignina evidentemente distorcerá todas estas estimativas de FDN indigerível. Os métodos gravimétricos de quantificação de lignina atualmente em uso necessitam de acurácia (Fukushima \& Dehority, 2000; Fukushima \& Hatfield, 2001). Recentemente, foram reportados resultados sobre uma técnica analítica alternativa, um método espectrofotométrico, que se mostraram promissores (Fukushima \& Hatfield, 2004; Hatfield \& Fukushima, 2005).

Outro ponto que têm suscitado discussões entre os pesquisadores é sobre o fator de correção originalmente sugerido por Chandler et al. (1980), baseado no resíduo indigerível de FDN após a fermentação prolongada de vários substratos por 90 ou 120 dias. Não há unanimidade neste valor de 2,4 e já foram sugeridos outros fatores de correção (Traxler et al., 1998; Malafaia et al., 1998; Fernandes et al., 2003). Se ocorrer um problema analítico na determinação quantitativa da lignina, obviamente este fator numérico também estará comprometido. Com esses problemas, alternativamente à estimação do conteúdo energético dos alimentos utilizando uma equação contendo dados de composição química dos alimentos, a fração C pode ser obtida pela determinação do teor de FDN indigerível após 96 horas (Fernandes et al., 2003; Pereira et al., 2000) ou 144 horas (Cabral et al., 2004; Azevêdo et al., 2003) de incubação. Embora possibilite reproduzir com maior fidelidade o real conteúdo de parede celular não digerível, esta metodologia é mais laboriosa. No entanto, pode ser empregada para validar a equação da fração $\mathrm{C}$. Equações baseadas na composição química para estimar o valor nutritivo e/ou o resíduo indigerível foram introduzidas com a justificativa de serem mais práticas e rápidas.

\section{Conclusões}

A irrigação aumenta vários parâmetros da composição química no girassol. Entretanto, os carboidratos totais, principalmente os açúcares, são encontradas em maior quantidade nas plantas cultivadas sem irrigação. A diferença PCcp - FDNcp fornece uma estimativa do teor de fibra solúvel, que inclui pectina, $\beta$-glucanas, fructanas e gomas. A utilização de parede celular em substituição à fibra em detergente neutro nas equações do CNCPS indica que a pectina nunca fez parte da fração $B_{1}$. Sugere-se que seja destinada uma fração exclusiva para a fibra solúvel, que poderia ser a fração $\mathrm{B}_{2}$. Para os carboidratos digeríveis da parede celular, uma nova fração, a fração $B_{3}$, seria criada. $A$ fração $\mathrm{B}_{1}$ seria constituída exclusivamente pelo amido; a equação da fração $C$, que estima os carboidratos indigeríveis da parede celular, pode ser simplificada, relacionando a fração indigerível em relação ao teor de lignina na matéria seca, e não na FDN isenta de cinzas e proteína.

\section{Literatura Citada}

AZEVÊDO, J.A.G.; PEREIRA, J.C.; QUEIROZ, A.C. et al. Composição químico-bromatológica, fracionamento de carboidratos e cinética da degradação in vitro da fibra de três variedades de cana-de-açúcar (Saccharum spp.). Revista Brasileira de Zootecnia, v.32, p.1443-1453, 2003.

BALSALOBRE, M.A.A.; CORSI, M.; SANTOS, P.M. et al. Composição química e fracionamento do nitrogênio e dos carboidratos do capim-Tanzânia irrigado sob três níveis de resíduo pós-pastejo. Revista Brasileira de Zootecnia, v.32, p. $519-528,2003$

BARCELOS, A.F.; PAIVA, P.C.A.; PÉREZ, J.R.O. et al. Estimativa das frações dos carboidratos da casca e polpa desidratada de café (Coffea arabica L.) armazenadas em diferentes períodos. Revista Brasileira de Zootecnia, v.30, p.1566-1571, 2001.

CABRAL, L.S.; VALADARES FILHO, S.C.; DETMANN, E. et al. Composição químico-bromatológica, produção de gás, digestibilidade in vitro da matéria seca e NDT estimado da silagem de sorgo com diferentes proporções de panículas. Revista Brasileira de Zootecnia, v.32, p.1250-1258, 2003.

CABRAL, L.S.; VALADARES FILHO, S.C.; DETMANN, E. et al. Taxas de digestão das frações protéicas e de carboidratos para as silagens de milho e de capim-elefante, o feno de capimTifton-85 e o farelo de soja. Revista Brasileira de Zootecnia, v.33, p.1573-1580, 2004.

CHANDLER, J.A.; JEWELL, W.J.; GOSSETT, J.M. et al. Predicting methane fermentation biodegradability. Biotechnology and Bioengineering Symposium, v.10, p.93-107, 1980.

CONRAD, H.R.; WEISS, W.P.; ODWONGO, W.O. et al. Estimating net energy lactation from components of cell solubles and cell walls. Journal of Dairy Science, v.67, p.427-436, 1984.

DETMANN, E.; ZERVOUDAKIS, J.T.; CABRAL, L.S. et al. Validação de equações preditivas da fração indigestível da fibra em detergente neutro em gramíneas tropicais. Revista Brasileira de Zootecnia, v.33, p.1866-1875, 2004.

EVANGELISTA, A.R.; LIMA, J.A. Cultivo e produção de silagem. A lavoura, v.104, p.29-33, 2001.

FERNANDES, A.M.; QUEIROZ, A.C.; PEREIRA, J.C. et al. Fracionamento e cinética da degradação in vitro dos carboidratos constituintes da cana-de-açúcar com diferentes ciclos de 
produção em três idades de corte. Revista Brasileira de Zootecnia, v.32, p.1778-1785, 2003 (supl.1).

FERREIRA, G.; MERTENS, D.R. Measuring detergent fibre and insoluble protein in corn silage using crucibles of filter bags. Animal Feed Science and Technology, v.133, p.335-340, 2007.

FOX, D.G.; SNIFFEN, C.J.; O'CONNOR, J.D. et al. A net carbohydrate and protein system for evaluating cattle diets: III. Cattle requirements and diet adequacy. Journal of Animal Science, v.70, p.3578-3596, 1992.

FOX, D.G.; TEDESCHI, L.O.; TYLUTKI, T.P. et al. The Cornell Net Carbohydrate and Protein System model for evaluating herd nutrition and nutrient excretion. Animal Feed Science and Technology, v.112, p.29-78, 2004.

FUKUSHIMA, R.S.; DEHORITY, B.A. Feasibility of using lignin isolated from forages by solubilization in acetyl bromide as a standard for lignin analyses. Journal of Animal Science, v.78, p.3135-3143, 2000.

FUKUSHIMA, R.S.; HATFIELD, R.D. Extraction and isolation of lignin and its utilization as standard to determine lignin concentration through a spectrophotometer method. Journal Agriculture and Food Chemistry, v.49, p.3133-3139, 2001.

FUKUSHIMA, R.S.; HATFIELD, R.D. Comparison of the acetyl bromide spectrophotometric method with other analytical lignin methods for determining lignin concentration in forage samples. Journal of Agricultural and Food Chemistry, v.52, p.37133720, 2004.

GIESY, J.G.; MCGUIRE, M.A.; SHAFII, B. et al. Effect of dose on calcium salts of conjugated linoleic acid (CLA) on percentage and fatty acid content of milk fat in midlactation Holstein cows. Journal of Dairy Science, v.85, p.2023-2029, 2002.

GOERING, G.K.; Van SOEST, P.J. Forage fiber analysis (apparatus, reagents, procedures and some applications). Washington, D.C.: US Department of Agriculture, 1970. (Agricultural Handbook, 379).

GONÇALVES, G.D.; SANTOS, G.T.; JOBIM, C.C. et al. Determinação do consumo, digestibilidade e frações protéicas e de carboidratos do feno de Tifton 85 em diferentes idades de corte. Revista Brasileira de Zootecnia, v.32, p.804-813, 2003.

GORSHKOVA, T.A.; WYATT, S.E.; SALINIKOV, V.V. et al. Cellwall polysaccharides of developing flax plants. Physiology, v.110, p.721-729, 1996.

HALL, M.B. Challenges with nonfiber carbohydrate methods. Journal of Animal Science, v.81, p.3226-3232, 2003.

HATFIELD, R.D.; FUKUSHIMA, R.S. Can lignin be accurately measured? Crop Science, v.45, p.832-838, 2005.

HENDRIX, D.L. Rapid extraction and analysis of nonstructural carbohydrate in plant tissues. Crop Science, v.33, p.1306-1311, 1993.

HINTZ, R.W.; MERTENS, D.R.; ALBRECHT, K.A. Effects of sodium sulfite on recovery and composition of detergent fiber and lignin. Journal of AOAC International, v.79, p.16-22, 1996.

LANZAS, C.; SNIFFEN, C.J.; SEO, S. et al. [2006]. A revised CNCPS feed carbohydrate fractionation scheme for formulating rations for ruminants. Disponível em: <http://doi:10.1016/j.anifeedsci.> Acesso em: 25/8/2006.

MALAFAIA, P.A.M.; VALADARES FILHO, S.C.; VIEIRA, R.A.M. et al. Determinação das frações que constituem os carboidratos totais e cinética ruminal da fibra em detergente neutro de alguns alimentos para ruminantes. Revista Brasileira de Zootecnia, v.27, p.790-796, 1998.

MERTENS, D.R. Gravimetric determination of amylase-treated neutral detergent fiber in feeds using refluxing in beakers or crucibles: collaborative study. Journal of AOAC International, v.85, p.1217-1240, 2002.
NOCEK, J.E.; RUSSELL, J.B. Protein and energy as an integrated system: relationship of ruminal protein and carbohydrate availability to microbial synthesis and milk production. Journal of Dairy Science, v.71, p.2070-2107, 1988.

NATIONAL RESEARCH COUNCIL - NRC. Nutrient requirements of dairy cattle. 7.ed. Washington, D.C.: National Academy Press, 2001. 381p.

PEREIRA, E.S.; QUEIROZ, A.C.; PAULINO, M.F. et al. Determinação das frações protéicas e de carboidratos e taxas de degradação in vitro da cana-de-açúcar, da cama de frango e do farelo de algodão. Revista Brasileira de Zootecnia, v.29, p.1887-1893, 2000.

PEREIRA, J.R.A.; ROSSI JR., P. Manual prático de avaliação nutricional de alimentos. Piracicaba: Fundação de Estudos Agrários Luiz de Queiroz, 1994. 34p.

RIBEIRO, K.G.; PEREIRA, O.G.; VALADARES FILHO, S.C. et al. Caracterização da frações que constituem as proteínas e os carboidratos e respectivas de digestão do feno de capim Tifton 85 de diferentes idades de rebrota. Revista Brasileira de Zootecnia, v.30, p.589-595, 2001.

RUSSELL, J.B.; O'CONNOR, J.D.; FOX, D.G. et al. A net carbohydrate and protein system for evaluating cattle diets: I. rumen fermentation. Journal of Animal Science, v.70, p.3551-3561, 1992.

STATISTICAL ANALYSIS SYSTEM - SAS. SAS/STAT User's guide. Version 6, 4.ed. Cary: SAS Institute, 1998. v.2, 1028p.

SILVA, D.J.; QUEIROZ, A.C. Análise de alimentos: métodos químicos e biológicos. 3.ed. Viçosa, MG: Editora UFV, 2002. $235 \mathrm{p}$.

SNIFFEN, C.J.; O'CONNOR, J.D.; Van SOEST, P.J. A net carbohydrate and protein system for evaluating cattle diets: II. carbohydrate and protein availability. Journal of Animal Science, v.70, p.3562-3577, 1992.

TOMICH, T.R.; GONÇALVES, L.C.; TOMICH, R.G.P. et al. Características químicas e digestibilidade in vitro de silagens de girassol. Revista Brasileira de Zootecnia, v.33, p.1672-1682, 2004 (supl.1).

TRAXLER, M.J.; FOX, D.G.; Van SOEST, P.J. et al. Predicting forage indigestible NDF from lignin concentration. Journal of Animal Science, v.76, p.1469-1480, 1998.

TYLUTKI, T.P.; FOX, D.G.; DURBAL, V.M. et al. [2007]. Cornell Net Carbohydrate and Protein System: a model for precision feeding of dairy cattle. Disponível em: <http://doi:10.1016/ j.anifeedsci> Acesso em: 10/5/2007.

Van SOEST, P.J. Use of detergents in the analysis of fibrous foods. II. A rapid method for the determination of fibre and lignin. Journal of Association of Official Analytical Chemists, v.46, p.829-835, 1963.

Van SOEST, P.J. Use of detergents in the analysis of fibrous foods. IV. Determination of plant cell wall constituents. Journal of Association of Official Analytical Chemists, v.50, p.5055, 1967a.

Van SOEST, P.J. Development of a comprehensive system of feed analyses and its application to forages. Journal of Animal Science, v.26, p.119-128, 1967b.

Van SOEST, P.J. Nutritional ecology of the ruminant. 2.ed. Ithaca: Cornell University Press, 1994. 476p.

Van SOEST, P.J.; ROBERTS, J.B.; LEWIS, B.A. Methods for dietary fibre, neutral detergent fibre and non-starch polysaccharides in relation to animal nutrition. Journal of Dairy Science, v.74, p.3583-3597, 1991.

WEISS, W.P.; CONRAD, H.R.; St. PIERRE, N.R. A theoreticallybased model for predicting total digestible nutrient values of forages and concentrates. Animal Feed Science and Technology, v.39, p.95-110, 1992.

WHITMORE, F.W. Lignin-protein complex in cell walls of Pinus elliotti: amino acid constituents. Phytochemistry, v.21, p.315$318,1982$. 